\title{
Effects of early surgical decompression on functional and histological outcomes after severe experimental thoracic spinal cord injury
}

\author{
*Devesh Jalan, MD, ${ }^{1}$ Neginder Saini, MS, ${ }^{1}$ Mohammad Zaidi, BA, ${ }^{1}$ Alexandra Pallottie, BA, ${ }^{2}$ \\ Stella Elkabes, PhD, ${ }^{1}$ and Robert F. Heary, MD' ${ }^{1}$
}

'Department of Neurological Surgery, Rutgers, The State University of New Jersey-New Jersey Medical School; and ${ }^{2}$ Graduate School of Biomedical Sciences, Rutgers, The State University of New Jersey, Newark, New Jersey

\begin{abstract}
OBJECTIVE In acute traumatic brain injury, decompressive craniectomy is a common treatment that involves the removal of bone from the cranium to relieve intracranial pressure. The present study investigated whether neurological function following a severe spinal cord injury improves after utilizing either a durotomy to decompress the intradural space and/or a duraplasty to maintain proper flow of cerebrospinal fluid.

METHODS Sixty-four adult female rats $(n=64)$ were randomly assigned to receive either a 3- or 5-level decompressive laminectomy (Groups A and B), laminectomy + durotomy (Groups C and D), or laminectomy + duraplasty with graft (Group E and F) at 24 hours following a severe thoracic contusion injury (200 kilodynes). Duraplasty involved the use of DuraSeal, a hydrogel dural sealant. Uninjured and injured control groups were included (Groups G, H). Hindlimb locomotor function was assessed by open field locomotor testing (BBB) and CatWalk gait analysis at 35 days postinjury. Bladder function was analyzed and bladder wall thickness was assessed histologically. At 35 days postinjury, mechanical and thermal allodynia were assessed by the Von Frey hair filament and hotplate paw withdrawal tests, respectively. Thereafter, the spinal cords were dissected, examined for gross anomalies at the injury site, and harvested for histological analyses to assess lesion volumes and white matter sparing. ANOVA was used for statistical analyses.
\end{abstract}

RESULTS There was no significant improvement in motor function recovery in any treatment groups compared with injured controls. CatWalk gait analysis indicated a significant decrease in interlimb coordination in Groups $B, C$, and $D(p<$ 0.05 ) and swing speed in Groups A, B, and D. Increased mechanical pain sensitivity was observed in Groups A, C, and $F(p<0.05)$. Rats in Group $C$ also developed thermal pain hypersensitivity. Examination of spinal cords demonstrated increased lesion volumes in Groups $C$ and $F$ and increased white matter sparing in Group $E(p<0.05)$. The return of bladder automaticity was similar in all groups. Examination of the injury site during tissue harvest revealed that, in some instances, expansion of the hydrogel dural sealant caused compression of the spinal cord.

CONCLUSIONS Surgical decompression provided no benefit in terms of neurological improvement in the setting of a severe thoracic spinal cord contusion injury in rats at 24 hours postinjury. Decompressive laminectomy and durotomy did not improve motor function recovery, and rats in both of these treatment modalities developed neuropathic pain. Performing a durotomy also led to increased lesion volumes. Placement of DuraSeal was shown to cause compression in some rats in the duraplasty treatment groups. Decompressive duraplasty of 3 levels does not affect functional outcomes after injury but did increase white matter sparing. Decompressive duraplasty of 5 levels led to neuropathic pain development and increased lesion volumes. Further comparison of dural repair techniques is necessary.

http://thejns.org/doi/abs/10.3171/2016.6.SPINE16343

KEY WORDS durotomy; duraplasty; DuraSeal; catwalk; contusion; pain; spinal cord injury; thoracic

\footnotetext{
ABBREVIATIONS BBB = Basso-Beattie-Bresnahan; CSF = cerebrospinal fluid; GFAP = glial fibrillary acidic protein; ICP = intracranial pressure; IH = Infinite Horizon; LSD = least significant difference; OCT = optimal cutting temperature; PBS = phosphate-buffered saline; PBS-T = PBS containing $0.1 \%$ Triton; $\mathrm{SCl}=$ spinal cord injury; SEM = standard error of the mean; TBI = traumatic brain injury.

SUBMITTED March 24, 2016. ACCEPTED June 20, 2016.

INCLUDE WHEN CITING Published online September 16, 2016; DOI: 10.3171/2016.6.SPINE16343.

* Dr. Jalan and Mr. Saini contributed equally to this work.
} 
$\mathrm{S}$ PINAL cord injury (SCI) is a debilitating condition with many associated comorbidities. In the United States, an estimated 282,000 people live with SCI and there are 17,000 additional individuals sustaining SCI each year. ${ }^{37}$ Emerging studies have shown the benefit of a variety of acute treatments including pharmacological therapies, cell transplantations, hypothermia, and surgical interventions.$^{50}$ In recent years, surgical decompression has become a mainstay of treatment for acute traumatic brain injury (TBI), and similar treatments have been considered for SCI with positive but guarded results. . $^{1,6,8,10,16 \text {, }}$ $22,31,48,53,58,61$

In patients with severe TBI, increased intracranial pressure (ICP) and hypertension are common causes of poor neurological outcomes and death. ${ }^{1,22,24,46,47,53}$ Cerebral ischemia and elevated ICP cause secondary injury, which

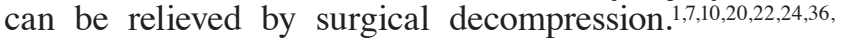
51,53,58,59,61,66 Craniectomy removes compressive elements from the tissue so that the edematous brain swells outward rather than downward, herniation is prevented, and adequate vascular perfusion is maintained..$^{10}$ Performing a durotomy in the craniectomy procedure provides the injured brain tissue with a larger space to swell, and the additional space helps to prevent continued mechanical damage to the tissue..$^{22,53}$ If the dura remains open, surgical complications such as cerebrospinal fluid (CSF) leaks can occur; ;,22,53 therefore, craniectomy and durotomy combined with an augmentative graft placement over the opening, referred to as a duraplasty or cranioplasty, are widely performed. . $^{1,2,10,21,22,42,52,53,58,61}$ Cranioplasty re-establishes the intra- and extracranial compartments and has led to improved outcomes and lower secondary surgical complications, but the optimal timing of cranioplasty in a setting of TBI has yet to be established. ${ }^{22,45,55,61}$

Treatments similar to those performed after TBI have been considered for SCI. ${ }^{8,12,16,19,31,44,51,58}$ Early bony decompression at 24 hours postinjury has been shown to have a positive effect on recovery after SCI..$^{15,16,31,51}$ In addition, the decrease in intradural pressure following durotomy allows for increased blood flow to the spinal cord, which prevents continued ischemic injury to the cord. ${ }^{12,15,22,42,51}$ These outcomes are potentially beneficial to the recovery of individuals who have sustained injury; however, no standards of care exist regarding the timing or role of surgical decompression in acute SCI. ${ }^{10,15,22,31,42}$ In an animal model of acute mild cervical SCI, Smith et al. demonstrated better functional recovery and decreased lesion size, inflammation, and scar formation following decompression of the intradural space using durotomy and placement of a dural graft compared with decompression with durotomy alone..$^{51}$ This was the first rodent study to address the role of decompression of the cervical spinal cord by means of a durotomy or duraplasty. ${ }^{51}$ The authors performed a surgical decompression treatment 4 hours following the initial injury; however, a major methodological concern in this study was that the animals were not allowed to fully recover from the anesthetic and undergo a neurological examination. As a result, if the animals sustained varying degrees of injury during the initial surgical procedure, the potential to bias results of one group relative to another was a concern. Additionally, in clinical practice, early surgical decompression is considered to be less than 24 hours, with some experts recommending decompression within 8-24 hours postinjury. ${ }^{19}$ Performing decompression within 4 hours following SCI as done by Smith et al. would be unfeasible in a clinical setting. ${ }^{62}$ Outcomes after duraplasty and durotomy treatments require further investigation; the hypothesis of this study was that duraplasty performed 24 hours postinjury will improve functional and histological outcomes in an animal model of acute severe thoracic SCI. To better understand the effects of multilevel decompression on functional and histological outcomes, decompression extending 3 and 5 levels at the site of injury was performed.

\section{Methods}

All animal protocols were approved by the Rutgers University Institutional Animal Care and Use Committee.

\section{Study Design}

A total of 64 adult (16-20 weeks old, weight 240-260 g), female Sprague-Dawley rats (Charles River Laboratories) were randomly assigned to 8 different groups: injured controls, uninjured controls, a 3- or 5-level laminectomy group, a 3- or 5-level laminectomy + durotomy group, or a 3- or 5-level laminectomy + durotomy + duraplasty group. All surgical procedures were performed by a single surgeon. All injuries were performed at the T-10 level utilizing the Infinite Horizon (IH) impactor (Precision Systems Inc.) with a force of 200 kilodynes. On the first day following the contusive injury, hindlimb locomotor testing using the Basso-Beattie-Bresnahan (BBB) open field locomotor rating scale was performed to ensure that equivalent injuries occurred in all rats included in the study. ${ }^{3}$ An additional 16 rats were used for harvesting of dura mater for transplantation (see Dural Harvest below).

All rats received twice-daily buprenorphine $(0.2 \mathrm{ml}$ of $0.03 \mathrm{mg} / \mathrm{ml}$ ) for analgesia; Baytril (enrofloxacin, $0.2 \mathrm{ml}$ of $2.5 \mathrm{mg} / \mathrm{ml}$ ) to prevent respiratory, soft tissue, and urinary tract infections; and $10 \mathrm{ml}$ of $0.9 \%$ normal saline for maintenance hydration for the first 7 postoperative days. Bladders were manually expressed twice daily, every 12 hours, to prevent urinary retention and bladder stone formation until bladder automaticity returned, which was typically between 10-14 days after the SCI. Rats were monitored and tested weekly from the day of injury for behavioral analyses until Day 35, after which they were killed by transcardial perfusion with $0.9 \%$ saline followed by $4 \%$ paraformaldehyde. Spinal cords and bladders were harvested, postfixed, cryoprotected and frozen. They were conserved at $-80^{\circ} \mathrm{C}$ for histological analyses.

\section{Randomization}

One laboratory member, not involved in the present investigations, created a master list of each study rat that met the inclusion criteria. Each rat was randomized to a treatment or control group and assigned two different codes. From this master list, 2 sets of codes were created and given to the surgical and behavioral observation teams. In this manner, communication was possible between teams, and the study was triple blinded. 


\section{Dural Harvest}

Sixteen adult naïve female Sprague-Dawley rats were administered a lethal, weight-based dose of ketamine and transcardially perfused with $60 \mathrm{ml}$ of $0.9 \%$ normal saline over a period of 4 minutes for exsanguination. The spinal cord was then exposed and 2.5-cm-long segments of dura mater were harvested. This generally yielded 2 segments of dura that were suitable for transplantation. The dura was rinsed in saline and pinned onto foam blocks. The dura was then conserved in $50 \mathrm{ml}$ conical tubes filled with $70 \%$ alcohol at $4{ }^{\circ} \mathrm{C}$ until use. Before transplantation, they were thoroughly rinsed with saline.

\section{Spinal Cord Injury}

All rats that were assigned to treatment groups were handled daily for 3 days to reduce stress and to habituate for behavioral testing, human handling, and drug administration. ${ }^{9}$ Subsequently, the rats were acclimated to the behavioral testing equipment to prevent fearful behaviors such as freezing or attempts to escape. All rat injuries were performed by a single surgeon in the same fashion. The rodents were weighed and a weight-based dose of ketamine/ xylazine $(60 \mathrm{mg} / \mathrm{kg})$ was administered via an intraperitoneal injection using sterile techniques. Effective anesthesia was confirmed by the absence of both hindlimb and corneal reflexes. The dorsal fur was then shaved from the pelvis to the occiput, in a $10 \mathrm{~cm} \times 4 \mathrm{~cm}$ strip. The shaved area was cleaned with iodine and alcohol, and the eyes were protected with petroleum jelly. The rat was transferred to the operating microscope (Leica Microsystems) on a heating pad (Gaymar) at $41^{\circ} \mathrm{C}$, with its core temperature monitored with a rectal probe and maintained at $37^{\circ} \mathrm{C}$. The T-2 spinous process was palpated and a uniform $6-\mathrm{cm}$ midline skin incision was made. Utilizing the same shave dimensions and length of skin incision allowed for blinded evaluations to occur in the postoperative follow-up period. The subcutaneous fat was bluntly dissected and the spinous processes were counted down from the T-2 process to the T-10 vertebral level. Sharp incision with a No. 15 blade scalpel was carried down to the bone bilaterally as close to the midline as possible. The muscle and fascia were then retracted. The T-10 spinous process and laminae were removed and the animal was affixed to the IH impactor frame at the T-9 and T-11 levels. At this point, the rat was moved to the impactor and the spinal cord impactor tip was centered over the laminectomy site, brought down until it almost touched the spinal cord, and then retracted $3 \mathrm{~mm}$. To induce injury, the impactor was set to a force of 200 kilodynes and a blunt contusion was induced. If the contusion curve was consistent with a normal hit, as determined by the force and displacement curves measured by the impactor software, the animal was transferred back to the operating microscope and a layered closure was performed..$^{48}$ The skin was closed with 12 EZ Clip staples (Stoelting Co.), which allowed all rats to have an identical appearance regardless of which treatment was subsequently administered to ensure that the observers evaluating the motor and sensory deficits remained blinded to the treatment. The rats in the uninjured control group underwent a T-10 laminectomy, but the impact was not administered. The purpose of the uninjured control group was to ensure that inadvertent injury was not caused by the laminectomy procedure or the induction of anesthesia prior to inducing the severe SCI with the impactor. Rats in the injured control group underwent a T-10 laminectomy with induction of injury but did not undergo any subsequent surgery. The rats in all groups were returned to their cages after the procedure and were kept on a heating pad until they fully recovered from anesthesia. For purposes of this manuscript, the term "postinjury" will be used in quantifying elapsed time since the above-described procedures for all animals, even those in the uninjured control group.

\section{Treatment Surgery}

At 24 hours postinjury, the rats were evaluated and scored on the BBB locomotor rating scale. ${ }^{3}$ Preliminary data from this laboratory were used to determine a postinjury Day 1 BBB score indicative of a 200-kilodyne impact. Our inclusion criteria were set at a postinjury Day 1 average BBB score of 0.5 , which corresponds to slight movement of 1 or 2 joints of 1 hindlimb and no motion of the other hindlimb. If the rat had a BBB score higher than 0.5 , as determined by 2 evaluators who were blinded to the treatment arm, it was not included in the study. These strict criteria ensured that all animals in the study had equivalent injuries prior to being randomized to a particular study group. Three rats had a Day 1 BBB score of 1 and were excluded. Ten rats had a BBB score of exactly 0.5 and were not concentrated in any particular treatment group. The rats that had a BBB score of 0 or 0.5 were taken back to the operating room and re-anesthetized as before. The staples were removed and the stitches cut out to expose the contusion. Rats in the control groups had their incisions re-sutured and closed as before and received postoperative drugs and bladder expression. Rats that were randomized to receive surgical treatment had their operative levels exposed and, depending on which group that they were assigned to, underwent additional laminectomies. Those receiving durotomy or duraplasty were then mounted on the impactor frame to minimize movement. A No. 11 blade scalpel (Feather) was then used to make a small incision in the dura under high magnification. An ophthalmological lens scraper (Moria Inc.) was gently inserted below the dura, and the scalpel was used to cut the dura over the lens scraper as it was advanced the length of the exposure. After this, rats in the duraplasty treatment group received a dural graft to cover the dural defect, with the graft being held in place by a thin layer of DuraSeal Exact spine sealant, a low-swell, polyethylene glycol hydrogel dural sealant (Integra). The incisions were closed and care was given as before.

\section{Postoperative Care and Monitoring}

All rats were given twice-daily care, including manual bladder expression, buprenorphine, Baytril, and $10 \mathrm{ml}$ normal saline, for a period of 7 days postinjury. Manual bladder expression continued twice daily until automaticity returned. The number of days until the return of bladder automaticity was noted and determined by visual observations of urination and palpation of bladders for urine retention. 


\section{BBB Open Field Locomotor Rating}

Acclimatization for the open field locomotor test involved placing the rodents in a circular 5-foot diameter, steel, flat bottom tub for 5 minutes at a time for a period of 3 days. All rats were evaluated for 4 minutes by 2 observers blinded to the treatments, using the BBB open field locomotor rating scale on Days 1, 7, 14, 21, 28, and 35 postinjury. The rats were scored for both the BBB scale and the BBB subscore. ${ }^{3}$

\section{CatWalk Gait Analysis}

All rats were evaluated with the CatWalk gait analysis system (Noldus). Evaluations were performed on Days 14, 21,28 , and 35 postinjury, after the rats showed enough locomotor recovery for the analysis of hindlimb footprints. An investigator placed the rat in one end of the walkway while another investigator monitored the rat's movement across the walkway. As soon as the rat reached the end of the walkway, it was removed and returned to the cage while the investigators ensured proper data acquisition. Run attempts were repeated until 3 runs, under 10 seconds in duration, were recorded for each rat. The following gait parameters were analyzed for motor assessment, summarized as the following: ${ }^{40}$

- Regularity index (RI): A percentage index for the degree of interlimb coordination during gait, as measured by the number of normal step sequence patterns (NSSP), multiplied by the number of paws and divided by the number of paw placements; RI $=100 \% \times($ NSSP $\times 4$ ) / number of paw placements.

- Swing speed: Speed of the paw during swing stance (centimeters per second).

- Stride length: Distance between 2 consecutive paw placements of the same paw (centimeters).

- Swing duration: Time interval between 2 consecutive paw placements of the same paw in which the paw is not in contact with the glass plate (seconds).

- Print intensity: Mean pressure exerted by 1 individual paw during the floor contact when crossing the walkway. Data analysis was performed by averaging the left and right hind paw print intensities and expressed in arbitrary units.

- Duty cycle: (duration of paw contact / time between consecutive paw contacts) $\times 100$. It is the percentage of the total cycle that a given paw is on the ground.

- Base of support: The distance between the mass-midpoints of 2 hind prints at maximum contact during each step cycle. The results from each step cycle are averaged and expressed in millimeters.

\section{Plantar Von Frey Testing}

Rats were acclimatized to the Von Frey enclosures (UGO Basile) for 15 minutes daily, during 3 consecutive days, prior to testing. At 35 days postinjury, a plantar Von Frey test was performed to determine mechanical allodynia. Rats were placed into the enclosures and were allowed to habituate for a period of 5 minutes. Von Frey hairs (North Coast Medical Inc.) starting at $1 \mathrm{~g}$ and increasing on a logarithmic scale were applied to the plantar aspect of each hind paw behind the foot pads until hind paw threshold was determined. This was defined as voluntary withdrawal of the paw due to pain and was confirmed by increasing the size of the hair to ensure the response was repeated. The test was performed by 2 blinded observers, one directly applying the Von Frey filaments, and the other watching the response and recording the values. Day 35 postinjury values were obtained, and the threshold in grams was logarithmically transformed to obtain values on a linear scale, and the differences for each hindlimb were calculated.

\section{Dorsal Von Frey Testing}

Rats were also assessed with Von Frey testing on the dorsum of both hind paws. Each rat was immobilized by wrapping a small towel around the head and neck, with the rat held vertically upright so that the hind paws were exposed and gently resting flat on a benchtop. A second experimenter applied the filaments to the midpoint of the dorsum of the foot and recorded the hindlimb withdrawal threshold, when the rat clearly withdrew the paw from the filament. The threshold in grams underwent logarithmic transformation to attain values on a linear scale and the differences from baseline for each hindlimb were calculated. To acclimate prior to testing, rats were wrapped in the surgical towel and held in place for a period of 5 minutes daily, for 3 days.

\section{Hot Plate Hind Paw Withdrawal Test}

To acclimate the rats to the hot plate procedure, they were placed on the hot plate inside a Plexiglas chamber at room temperature for a period of 5 minutes daily, for 3 days prior to testing. To evaluate thermal sensitivity, all rats were subjected to the hot plate paw withdrawal test at a temperature of $55^{\circ} \mathrm{C}$ at 35 days postinjury. The test was performed by 2 blinded observers. Paw withdrawal latency was recorded when one of the observers witnessed a withdrawal of a hindlimb, licking of the paws, or an escape attempt. If none of these behaviors were manifested, the rat was removed from the hotplate after 30 seconds to prevent tissue injury.

\section{Perfusion and Harvest}

All rats were killed and tissue was harvested following completion of behavioral assessments at 35 days postinjury. Rats were given a lethal dose of ketamine/xylazine $(\sim 160 \mathrm{mg} / \mathrm{ml})$ intraperitoneally, and perfused transcardially with $60 \mathrm{ml}$ of $0.9 \%$ normal saline during a period of 4 minutes, followed immediately by $125 \mathrm{ml}$ of ice-cold $4 \%$ paraformaldehyde in $0.01-\mathrm{M}$ phosphate buffer, $\mathrm{pH}$ 7.5 (PFA). A spinal cord segment from the T-8 through $\mathrm{T}-12$ levels and the urinary bladders were removed. These were postfixed overnight in 4\% PFA. The tissue was cryoprotected with $30 \%$ sucrose solution. and then frozen in optimal cutting temperature (OCT) compound (Sakura Finetek USA, Inc.). To ensure adequate freezing and to prevent damage and loss of tissue, the bladders were injected with OCT using an 18-gauge needle. Frozen specimens were placed into boxes and stored at $-80^{\circ} \mathrm{C}$ until sectioning. 


\section{Immunohistochemistry}

Immunohistochemical staining for glial fibrillary acidic protein (GFAP) was performed on specimens from all groups. Thirty-micrometer-thick axial sections were stained at $480-\mu \mathrm{m}$ intervals. Sections were blocked with $30 \%$ normal goat serum (NGS, Vector Laboratories) in phosphate-buffered saline containing $0.1 \%$ Triton (PBST) for 1 hour at room temperature. The slides were then decanted and incubated overnight at $4^{\circ} \mathrm{C}$ with polyclonal rabbit anti-GFAP diluted 1:5000 (Dako) in 1.5\% NGS, PBS-T solution. The following day the slides were washed 3 times with PBS-T and incubated with a secondary antibody, Alexa Fluor 488-tagged donkey anti-rabbit IgG, diluted 1:500 (Life Technologies) for 1 hour at room temperature. They were then washed 3 more times and coverslipped with Prolong Diamond anti-fade reagent (Life Technologies).

\section{Luxol Fast Blue Stain}

After the lesion epicenter was identified using GFAP staining, 30- $\mu \mathrm{m}$-thick axial sections were obtained at 480$\mu \mathrm{m}$ intervals and stained with Luxol fast blue (Sigma-Aldrich) to assess for spared white matter. The slides were thawed on a slide warmer at $37^{\circ} \mathrm{C}$ for 1 hour. Next, they were washed in PBS 3 times for 5 minutes each, followed by one 5-minute wash in deionized $\mathrm{H}_{2} \mathrm{O}$. The sections were then dehydrated in solutions with increasing concentrations of ethanol followed by a 5-minute incubation in xylenes. They were then rehydrated in solutions with decreasing concentration of ethanol for 2 minutes each before incubation in Luxol fast blue for 12 hours at $58^{\circ} \mathrm{C}$. The slides were rinsed with $95 \%$ ethanol for 2 minutes followed by deionized $\mathrm{H}_{2} \mathrm{O}$ for 2 minutes. Finally, the slides were developed in $0.05 \%$ lithium carbonate solution for 5 minutes followed by $70 \%$ alcohol for 5 minutes, and rinsed with deionized $\mathrm{H}_{2} \mathrm{O}$ for 30 seconds. Slides were coverslipped with Permount (Fisher Scientific) and stored at $4^{\circ} \mathrm{C}$.

\section{Hematoxylin and Eosin Staining}

Urinary bladder sections were stained with hematoxylin and eosin (H \& E). Five randomly selected $10-\mu \mathrm{m}-$ thick axial sections were dehydrated in ethanol, treated with xylenes for 5 minutes and subsequently rehydrated in ethanol. They were then rinsed with tap water and transferred to hematoxylin (Anatech Ltd.) for 5 minutes, followed by 3 tap water rinses. The slides were then dipped in $0.5 \%$ acetic acid in ethanol (acid ethanol) 5 times and rinsed in tap water 3 times. Next, the slides were dipped in ammonia water until blue, rinsed twice in tap water and then in $95 \%$ alcohol for 2 minutes before being stained with eosin (Anatech Ltd.) for 15 seconds. They were then rinsed with $95 \%$ ethanol followed by $100 \%$ ethanol for 2 minutes each. After three 3-minute washes in xylenes, they were coverslipped with Permount (Fisher Scientific).

\section{Imaging}

All photographic images were captured with a Leica DM 5500 B (Leica Microsystems) microscope at 50x magnification. The images were analyzed with ImageJ software (National Institutes of Health). For lesion vol- ume, a freehand selection tool was used to calculate the GFAP-negative area surrounded by an area of increased staining, which corresponded to reactive astrogliosis. This value was taken for each section and multiplied by the interval to the next measured section. The $480-\mu \mathrm{m}$ deep segments were then added together to calculate the total volume of the lesion. For white matter sparing, the freehand selection tool was used to outline the area of white matter, and the same measurement steps used for lesion volume were performed to calculate total volume of white matter spared. Bladder wall thickness was computed by measuring the width of the muscular layer of the wall with the straight line tool over the 5 sections, and the values were averaged for each rat.

\section{Adverse Events}

During the course of the study, 13 rats died prematurely and had to be replaced. The causes of death were as follows: lower limb autophagy (6 rats), urinary obstruction secondary to bladder stone formation (4 rats), pulmonary embolism (1 rat), large intestinal hemorrhage (1 rat), and not eating (1 rat). In the 3-level duraplasty and 5-level durotomy groups, a replacement rat in each group died prematurely during surgery as well; however, these animals were not replaced and thus the sample size remained at 7 for these 2 groups. The rats that died prematurely were not concentrated in any particular group and their deaths occurred throughout the course of the study. All causes of death were determined by autopsy.

\section{Statistical Analysis}

Motor function assessments with open field locomotor testing and CatWalk gait performed on Days 7, 14, 21, and 28 postinjury indicated no differences between groups. Therefore, data used for statistical analysis were obtained from behavioral assessments completed at 35 days postinjury. The uninjured control group was not included in the statistical analyses. All analyses were performed using SPSS version 22 (IBM, Inc.). One-way ANOVA was performed with a $\mathrm{p}$ value of 0.05 set as the level of significance, with Fisher's least significant difference (LSD) post hoc analysis. Histograms were created using GraphPad Prism (version 4.0, GraphPad Software, Inc.).

\section{Results \\ Motor Function \\ BBB Scores}

No change in hindlimb locomotor function was observed in uninjured controls throughout the course of the study. These rats had a mean score $( \pm$ standard error of the mean $[\mathrm{SEM}])$ of $21.0 \pm 0.0$, the highest attainable score on the BBB locomotor rating scale. There were no significant differences in BBB score for any of the treatment groups compared with injured controls (Fig. 1A). No significance was found in BBB subscores either (results not shown).

\section{CatWalk Gait Analysis}

The CatWalk data indicated a significant decrease in 

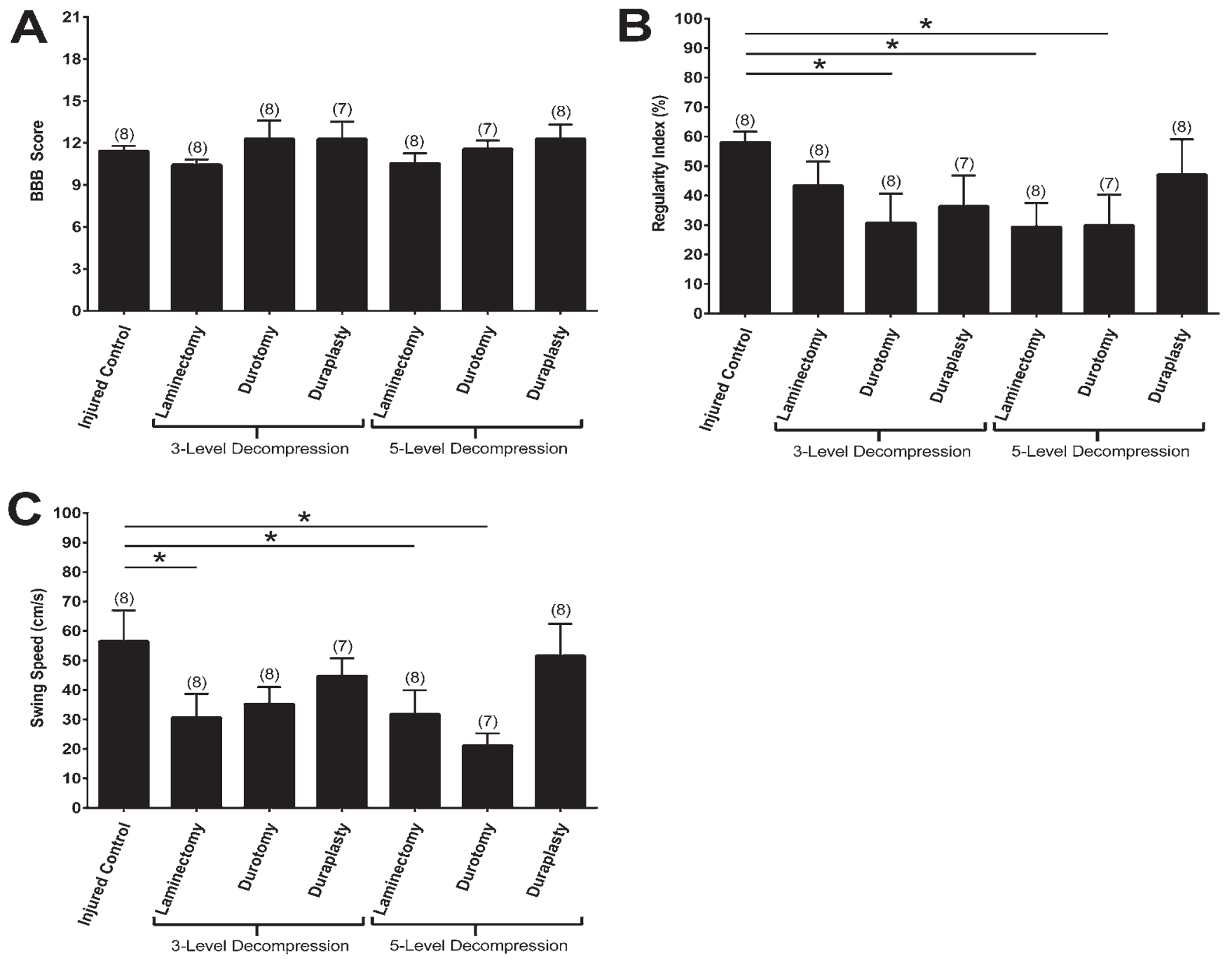

FIG. 1. Motor assessment. Effects of surgical decompression treatments on hindlimb locomotor function assessed by open field testing (BBB) (A) and regularity index (B) and swing speed (C) assessed by CatWalk gait analysis at 35 days after SCl. Values represent means \pm SEM (error bars). The number of rats in each group is shown in parentheses. Asterisk indicates significantly different by 1 -way ANOVA with Fisher LSD post hoc test $(p<0.05)$.

regularity index in the 3-level durotomy, 5-level laminectomy, and 5-level durotomy groups compared with injured controls $\left(\mathrm{F}_{6,47}=1.389, \mathrm{p}<0.05\right)$ (Fig. 1B). There was also a significant decrease in swing speed in the 3-level laminectomy, 5-level laminectomy, and 5-level durotomy groups compared with injured controls $\left(\mathrm{F}_{6,47}=2.444, \mathrm{p}<0.05\right)$ (Fig. 1C).

The additional CatWalk parameters (stride length, swing duration, print intensity, duty cycle, and base of support) showed no significant differences among any groups. The decrease in stride length of the 5-level laminectomy and 5-level durotomy groups compared with results in injured controls showed a trend toward statistical significance ( $p=0.06$ and $p=0.08$, respectively). The decrease in print intensity of the 5-level laminectomy and 5-level durotomy groups compared with injured control also showed a trend toward statistical significance $(p=0.07$ and $p=$ 0.08 , respectively).

\section{Sensory Function}

Hot Plate Paw Withdrawal Test

Uninjured controls and injured control groups showed no significant differences between threshold values for mechanical and thermal pain sensitivity tests, indicating that in our paradigm SCI does not induce neuropathic pain. There was a significant decrease in paw withdrawal latency in the 3-level durotomy group compared with injured controls $\left(\mathrm{F}_{6.47}=2.502, \mathrm{p}<0.05\right)$ in the hotplate paw withdrawal test (Fig. 2 upper). The decrease in paw withdrawal latency of the 3-level laminectomy and 5-level duraplasty group compared with injured controls showed a trend toward statistical significance $(\mathrm{p}=0.06$ and $\mathrm{p}=0.08$, respectively).

\section{Von Frey Test}

Plantar Von Frey data obtained at 35 days postinjury showed no differences between any groups. Dorsal Von 
Frey data obtained at 35 days postinjury showed a significant decrease in the painful paw withdrawal response threshold in the 3-level laminectomy, 3-level durotomy, and 5-level duraplasty groups compared with injured controls $\left(\mathrm{F}_{6,47}=2.564, \mathrm{p}<0.05\right)$ (Fig. 2 lower).

\section{Autonomical Function}

There were no significant differences between any groups for the numbers of days taken to recover bladder automaticity function.

\section{Histological Analyses}

During gross examination of the dissected spinal cords after perfusion, it became apparent that 4 rats in each duraplasty treatment group (Groups E and F) had adverse spinal cord compression due to the swelling of the hydrogel dural sealant. The swollen, fluid-filled hydrogel dural sealant, found on the compressed spinal cords, prevented proper embedding of the tissue in OCT compound for freezing and interfered with frozen tissue sectioning on a cryostat. Even though we obtained sections from some of the compressed spinal cords, the extensive compression prevented proper visualization and quantitative assessment of the histological parameters. Therefore, these specimens could not be processed and were excluded from the histological studies. In contrast, all but one of the noncompressed spinal cords were successfully frozen, sectioned; the exception was a noncompressed spinal cord from a rat in the 5-level duraplasty group that was damaged during handling, and this spinal cord was also excluded from the histological analysis. Due to the exclusion of some of the compressed or damaged cords, histological analyses were performed only on tissue obtained from 3 rats in the 3-level duraplasty group and 3 rats in the 5-level duraplasty group. Rats in the duraplasty treatment group that did not have spinal cord compression are referred to as "duraplasty without compression" and are labeled in the figures as "Duraplasty w/o comp." Due to technical issues with the $-80^{\circ} \mathrm{C}$ freezer, 1 spinal cord in the 3-level laminectomy, 2 spinal cords in the 3-level durotomy, and 2 spinal cords in the 5-level durotomy treatment groups were also excluded.

\section{Lesion Volume}

There was a significant increase in lesion volumes in the 3-level durotomy and 5-level duraplasty groups compared with injured controls $\left(\mathrm{F}_{6,34}=1.520, \mathrm{p}<0.05\right)$. The mean lesion volume $( \pm \mathrm{SEM})$ was $4.94 \pm 0.38,5.43 \pm 1.13$ and $3.58 \pm 0.39 \mathrm{~mm}^{3}$ for the 3-level durotomy, 5-level duraplasty, and injured control groups, respectively (Fig. 3A). Of note, only the duraplasty animals without significant spinal cord compression from swelling of the dural sealant were assessed for this portion of the results.

\section{White Matter Sparing}

White matter sparing measurements showed significantly higher sparing in the 3-level duraplasty group compared with injured controls $\left(\mathrm{F}_{6,34}=1.697, \mathrm{p}<0.05\right)$. The mean white matter sparing volume $( \pm$ SEM) was $23.01 \pm$ 4.01 and $14.66 \pm 1.65 \mathrm{~mm}^{3}$ for the 3-level duraplasty and injured control groups, respectively (Fig. 3B). Once again,
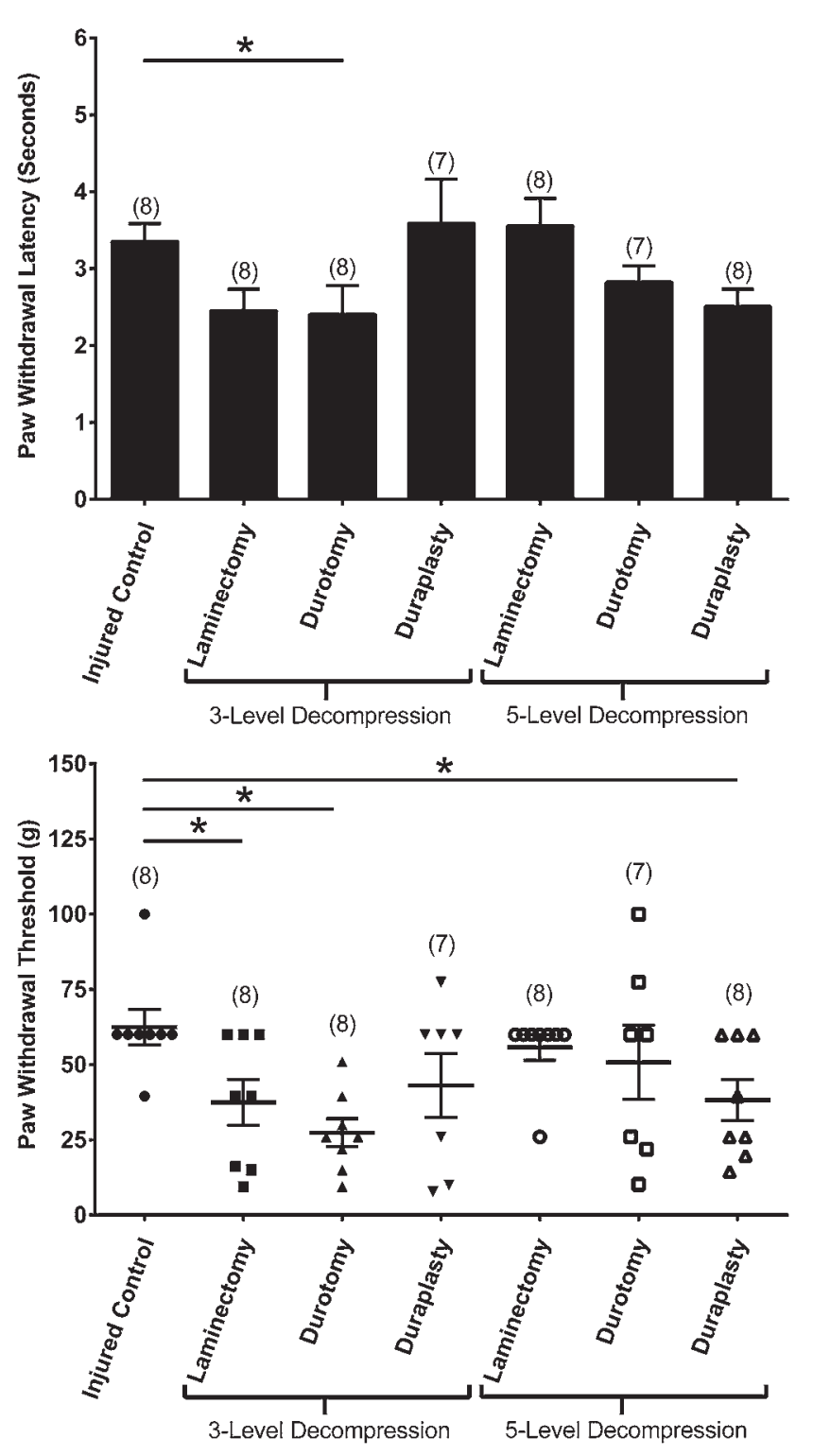

FIG. 2. Sensory assessment. Effects of surgical decompression treatments on (upper) hind paw withdrawal latency tested by hot plate test and (lower) mechanical pain threshold assessed by dorsal Von Frey test at 35 days after $\mathrm{SCl}$. Values represent means $\pm \mathrm{SEM}$ (error bars). The number of rats in each group is shown in parentheses. Asterisk indicates significantly different by 1 -way ANOVA with Fisher LSD post hoc test ( $p$ $<0.05)$.

only the duraplasty animals without significant spinal cord compression from swelling of the dural sealant were assessed for this portion of the results.

\section{Bladder Wall Thickness}

Due to the lack of a significant difference in the return to bladder automaticity, a subset of each group (3 rats per group) was used for bladder wall thickness analysis. Measurements showed significantly increased thickness in rats from the 3-level laminectomy group compared with injured controls $\left(\mathrm{F}_{6,14}=3.266, \mathrm{p}<0.05\right)$. The mean \pm SEM bladder wall thickness was $0.74 \pm 0.11$ and $0.52 \pm 0.07$ 

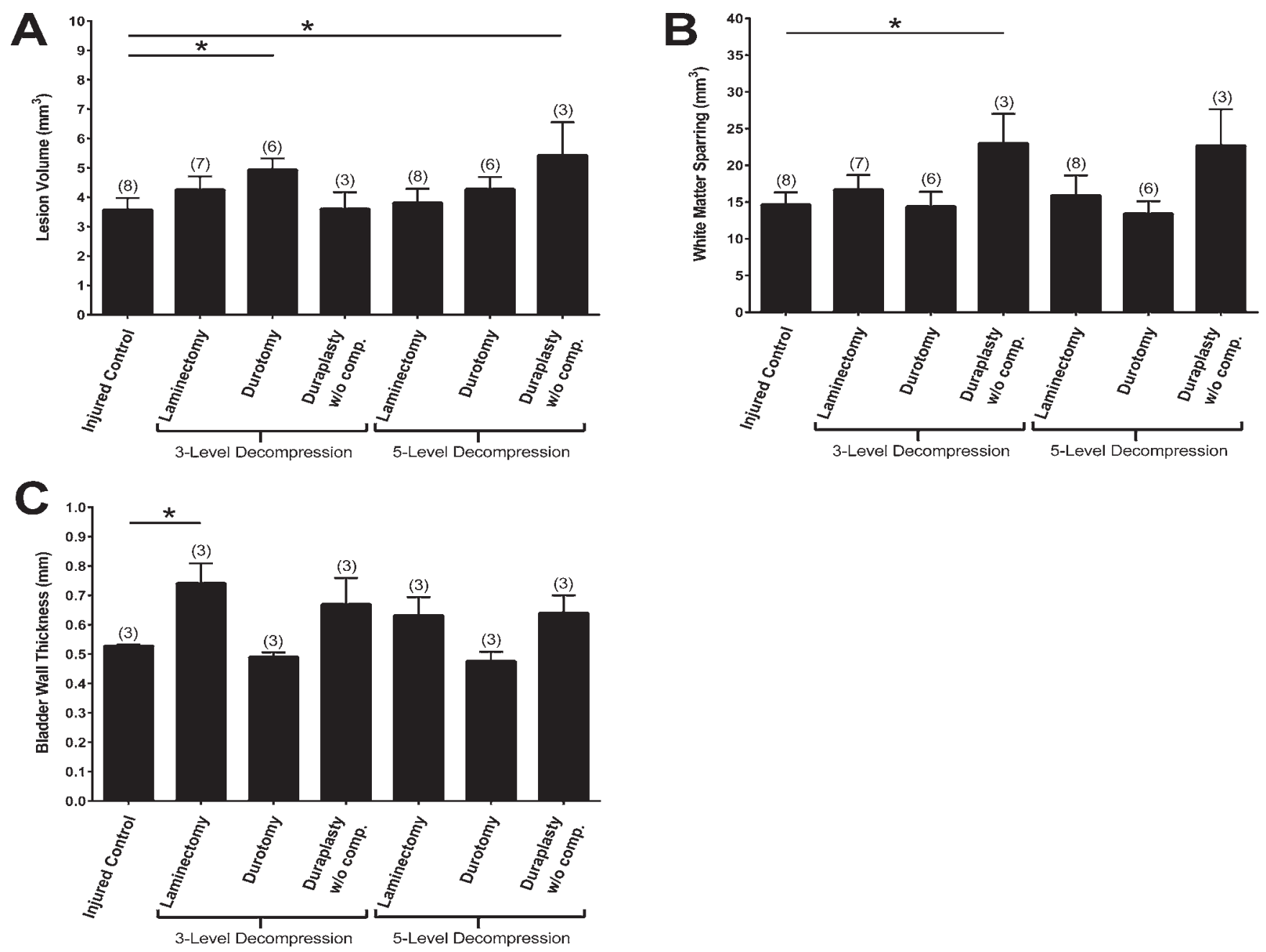

FIG. 3. Histological assessment. Effects of surgical decompression treatments on lesion volume (A), white matter sparing (B), and bladder wall thickness $(\mathbf{C})$ at 35 days after SCI. Values represent means \pm SEM (error bars). The number of rats in each group is shown in parentheses. Damage to specimens due to hydrogel dural sealant swelling limited analysis to 3 specimens per duraplasty group. Asterisk indicates significantly different by 1-way ANOVA with Fisher LSD post hoc test $(p<0.05)$. w/o comp. = without compression.

$\mathrm{mm}$ for animals from the 3-level laminectomy and injured control groups, respectively (Fig. 3C).

\section{Summary}

The results of all behavioral tests and histological analyses performed on all the groups are summarized in Table 1. Representative histological images of the injured control, duraplasty without compression, and duraplasty with compression spinal cords are presented in Fig. 4.

\section{Alternative Analysis}

Due to unanticipated complications with the hydrogel dural sealant, an additional statistical analysis was performed to observe the effects of 3- and 5-level duraplasty treatment on functional outcomes in instances where there was no adverse spinal cord compression. In this additional analysis, data from rats with compressed spinal cords in the duraplasty treatment groups were not included. The analysis included data obtained from rats without compression from the dural sealant and this subgroup was la- beled in Fig. 5 as "Duraplasty without compression (w/o comp)." Following these changes, statistical significance changed only in the hindlimb motor function and Von Frey tests (Fig. 5).

In the alternative analysis, the average BBB score for the 3-level duraplasty group was significantly higher than for the injured controls $\left(\mathrm{F}_{6,39}=2.255, \mathrm{p}<0.05\right)$ (Fig. 5A). Plantar Von Frey testing at 35 days postinjury showed a significant increase in the pain response threshold in the 5-level duraplasty treatment group compared with injured controls $\left(\mathrm{F}_{6,39}=2.530, \mathrm{p}<0.05\right)$ (Fig. 5B). Dorsal Von Frey testing at 35 days postinjury showed a significant decrease in the pain response threshold in the 3-level laminectomy and 3-level durotomy groups compared with injured controls $\left(\mathrm{F}_{6,39}=3.253, \mathrm{p}<0.05\right)$ (Fig. 5C).

\section{Discussion}

The results of this study do not support our hypothesis that early decompression of the intradural space improves 
TABLE 1. Summary of the results of behavioral testing and histological analysis after $\mathrm{SCl}^{*}$

\begin{tabular}{|c|c|c|c|c|c|c|c|c|}
\hline Group & BBB & RI & SS & Hot Plate HPW Latency & PVF Threshold Force & DVF Threshold Force & LV & WMS \\
\hline \multicolumn{9}{|l|}{ Injured control (8) } \\
\hline 3-level laminectomy (8) & & & $\downarrow$ & & & $\downarrow$ & & \\
\hline 3-level durotomy (8) & & $\downarrow$ & & $\downarrow$ & & $\downarrow$ & $\uparrow$ & \\
\hline 3-level duraplasty (7) & & & & & & & & $\uparrow$ \\
\hline 5-level laminectomy (8) & & $\downarrow$ & $\downarrow$ & & & & & \\
\hline 5-level durotomy (7) & & $\downarrow$ & $\downarrow$ & & & & & \\
\hline 5-level duraplasty (8) & & & & & & $\downarrow$ & $\uparrow$ & \\
\hline
\end{tabular}

BBB = Basso, Beattie, Bresnahan locomotive score; DVF = dorsal Von Frey; HPW = hind paw withdrawal; $\mathrm{LV}=$ lesion volume; $\mathrm{PVF}=$ plantar Von Frey; RI = regularity index (\%); SS = swing speed; WMS = white matter sparing; $\uparrow, \downarrow=$ significant $(p<0.05)$ increase or decrease, respectively, compared to injured controls.

* The number of rats in each group is indicated in parentheses. Absence of an arrow in any given cell indicates that for that group and variable there was no significant increase or decrease in response relative to that of controls.

outcomes. The rationale was that the early surgery would relieve compressive forces that contribute to secondary injury. Decompression with laminectomy followed by durotomy and duraplasty did not provide functional benefits. Although duraplasty was associated with less negative outcomes than laminectomy or durotomy, positive outcomes were observed in too few functional and histological assessments to conclude that this treatment provides a significant therapeutic benefit.

\section{Early Decompressive Laminectomy and Durotomy Treatments Lead to Negative Outcomes}

Early decompressive treatments with 3- and 5-level laminectomy and durotomy led to poor functional outcomes when compared with injured controls according to the CatWalk results. However, significant differences were not observed in the open field locomotor test using the BBB locomotor rating scale. ${ }^{3}$ It is possible that the standard BBB scale is insensitive to subtle motor differences. Koopmans et al. indicated that the regularity index parameter from CatWalk data can be used to measure interlimb coordination as an alternative to the established BBB score. ${ }^{28}$ This parameter appears to be a more sensitive indicator of interlimb coordination than the standard BBB score.

Additionally, there were sensory deficits following laminectomy and durotomy treatments. The 3-level laminectomy group manifested mechanical allodynia but not thermal hyperalgesia. It is possible that the intact dura caused continued spinal cord compression by constraining the swelling spinal cord. ${ }^{32}$ Additionally, due to the nature of the contusion injury, the dorsal column tracts may be more affected than the lateral spinothalamic tracts, which convey mechanical and painful-stimulus information, respectively. ${ }^{60}$ Treatment with 3-level durotomy was associated with the development of mechanical allodynia, thermal
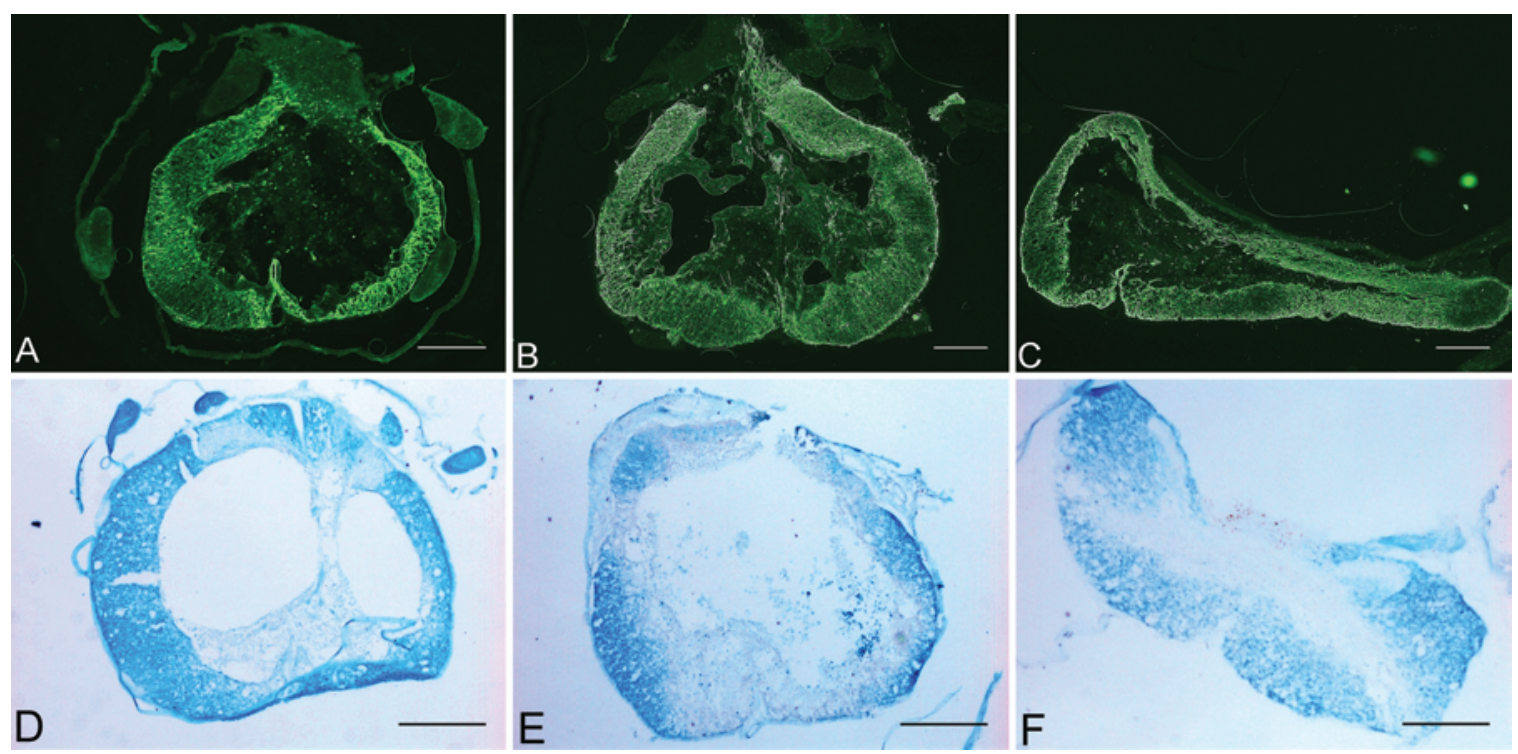

FIG. 4. Photomicrographs. Immunohistochemistry with anti-GFAP staining to label astroglia and delineate lesion boundaries (A-C) and Luxol fast blue stain for white matter sparing (D-F). Representative images of the lesion epicenter of injured control (A and D) and duraplasty treatment noncompressed ( $\mathrm{B}$ and $\mathrm{E}$ ) and compressed ( $\mathrm{C}$ and $\mathrm{F}$ ) spinal cords at $50 \times$ magnification. The top of the image corresponds to dorsal spinal cord. Scale bar $=500 \mu \mathrm{m}$. 

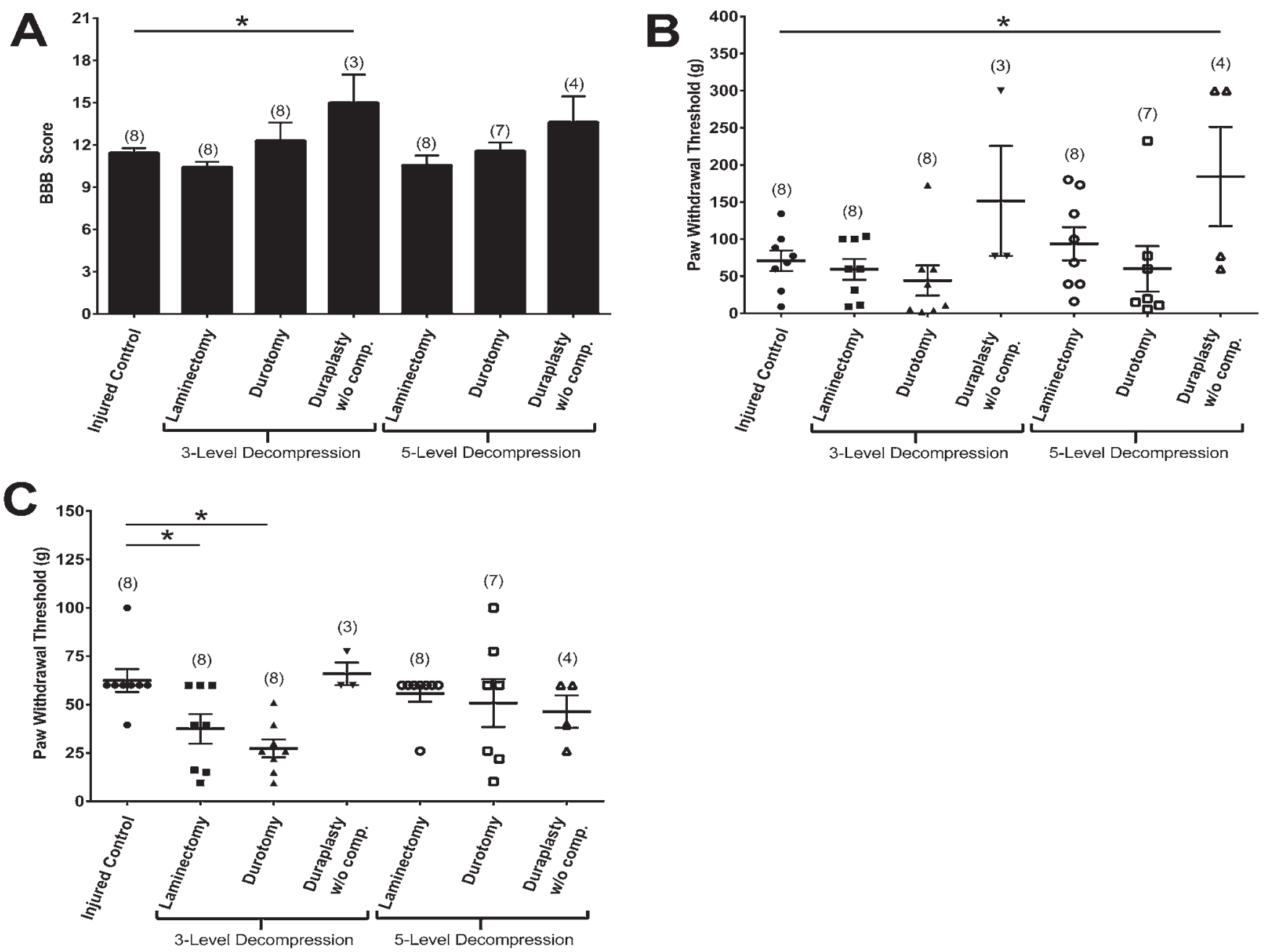

FIG. 5. Motor and sensory assessment without spinal cord compression. Effects of surgical decompression treatments on hindlimb locomotor function assessed by open field testing (BBB) (A) and mechanical pain threshold assessed by plantar (B) and dorsal (C) Von Frey testing. Values in Panel A represent means \pm SEM. In Panels B and C, circles, squares, and triangles indicate the data points for individual animals and the horizontal lines indicate means \pm SEM. The number of rats in each group is shown in parentheses. Statistical analysis performed with compressed spinal cord data excluded from duraplasty treatment groups. Asterisk indicates significantly different by 1 -way ANOVA with Fisher LSD post hoc test $(p<0.05)$. w/o comp. = without compression.

hyperalgesia, and increased lesion volume. It is speculated these poor outcomes result from performing a durotomy because of the loss of the continuity of the dura. ${ }^{51}$ Sensory dysfunction was not observed after treatment with 5-level laminectomy or durotomy. It is possible that the 5-level decompressive treatments created segmental instability which further damaged the spinal cord, interfering with signaling in the dorsal column and spinothalamic tracts. ${ }^{13,23,65}$ Furthermore, intersubject variability in susceptibility and responsiveness to pain could have contributed to the observed results. $1,14,33,36,38$

Lesion volume is indicative of tissue loss as a result of cell death following SCI. Previous studies have shown that lesion size correlates well with behavioral outcomes. $.^{26} \mathrm{Le}-$ sion volume and neuropathic pain were increased for both 3-level durotomy and 5-level duraplasty groups. Our results indicate that loss of an intact dura was detrimental to functional and histological recovery, and this is consistent with previously reported studies. ${ }^{25,51}$
Previous investigations have also shown that early recovery of controlled voiding is predictive of motor recovery; ${ }^{18,35}$ in our study, however, there was no significant difference between groups in the number of days to return of bladder automaticity. Histological analysis indicated a significant increase in bladder wall thickness for the 3-level laminectomy group, but since this did not translate into functional differences, it is difficult to draw conclusions on the effects of decompression on autonomic function . Previous studies indicate that SCI initially produces a period of bladder areflexia during which there is significant retention, with large residual urine volumes that cause bladder hypertrophy. ${ }^{17}$ Eventually this period is followed by emergence of the spinal micturition reflex and voluntary bladder voiding. We postulated that surgical decompression would improve autonomic function after SCI, leading to a faster return of voluntary bladder control as well as decreased bladder wall thickness due to less urinary retention. 
Simply expanding the intra- and extradural space following SCI may not be sufficient to improve outcomes, as shown by the lack of consistent positive outcomes in the laminectomy and durotomy groups. Possible explanations include an increased effect of the inflammatory response postinjury, leakage of CSF, and postoperative adhesions that may affect the flow of CSF around the injury site.

\section{Adverse Effects Are Associated With Hydrogel Dural Sealant Used for Early Decompressive Duraplasty Treatments}

During tissue harvest for histological analysis, several rats in the duraplasty treatment group appeared to have a compressed spinal cord caused by expansion of the hydrogel dural sealant. The DuraSeal spine sealant system product was first approved in 2005 by the US Food and Drug Administration (FDA) as an adjunct to sutured dural repair during spinal surgery to prevent CSF leaks by forming a watertight closure. Initial clinical studies indicated that it was safe and effective for providing watertight dural closure. ${ }^{5,11,56}$ However, from 2007 through 2010, multiple studies documented complications, such as spinal cord compression, caused by postapplication swelling of the product. ${ }^{4,29,34,57}$ The manufacturer, Covidien, announced in 2011 that a new, low-swell formulation of the hydrogel dural sealant was approved by the FDA. Kim and Wright, ${ }^{27}$ Osbun et al. ${ }^{41}$ and Wright et al.$^{64}$ concluded that the new DuraSeal product was superior to other standard-of-care methods to obtain a watertight dural closure and no neurological deficits were attributed to the sealant during spinal surgery. The incidence of neurosurgical complications, surgical-site infections, and CSF leaks using the hydrogel sealant was not statistically different from those observed with common dural sealing techniques..$^{27,41}$ Based on these findings, this new product, referred to as DuraSeal Exact spine sealant, was used in the present study. However, adverse effects related to swelling with spinal cord compression were still observed. More recent studies advise caution during application of DuraSeal and 2 case reports, published in 2012 and 2013, reported postoperative compression of the thecal sac by DuraSeal. ${ }^{30,39,49}$

The findings of the present study are in disagreement with those of Smith et al., ${ }^{51}$ who reported that functional recovery improved after acute cervical SCI in animals treated with duraplasty with dural allograft compared with durotomy alone. That study performed decompression on the cervical spine region, and the fibrin sealant used was manufactured by a different company (Tisseel, Baxter BioScience). It is possible that in the present study, different outcomes would have been observed if a different sealant was used for dural repair. ${ }^{49,51}$ Interestingly, in our study, the subset of animals that received DuraSeal but did not have evidence of swelling with associated spinal cord compression showed significantly improved motor function recovery compared with injured controls. However, there was no ability to predict which animals would be susceptible to the swelling complication because the technique employed in all surgeries was identical, with a thin layer of the DuraSeal applied. The possibility of postoperative expansion of DuraSeal is a serious concern and it is clear that the use of this sealant product is not an effec- tive dural repair technique in the spinal cord of rats in the model used in this study.

\section{Early Decompressive Duraplasty Treatments Lead to Negative and Positive Outcomes}

Motor assessments indicated that 3- and 5-level duraplasty treatments did not significantly affect recovery of hindlimb locomotor function. Duraplasty with 3-levels of decompression did not cause development of neuropathic pain and it increased white matter sparing at the lesion area. Although the 3-level duraplasty did not negatively affect functional outcomes, the 5-level treatment resulted in the development of mechanical allodynia and increased lesion volume. Stromqvist et al. concluded that the incidence of dural lesions increased with the number of levels decompressed in patients undergoing decompressive surgery for lumbar spinal stenosis. ${ }^{54} \mathrm{We}$ postulate that performing a 5-level decompression increased segmental instability and worsened neurological outcomes in terms of increased lesion volume and mechanical allodynia. In clinical practice, multilevel laminectomies are augmented with spinal fusion and instrumentation to address any instability issues, but this was not feasible in a rat model, and this difference may explain the lack of functional outcomes following 5-level treatments. ${ }^{63}$

\section{Possible Functional Benefits Exist With Early Decompressive Duraplasty Treatment When No Adverse Hydrogel Dural Sealant Effects Are Observed}

An additional statistical analysis was performed to demonstrate the impact of spinal cord compression caused by swelling of DuraSeal hydrogel dural sealant on behavioral outcomes. Motor function following 5-level duraplasty without compression was not significantly different compared with injured controls. However, there was improvement of motor function following 3-level duraplasty without compression and no development of pain. This may be due to decreased pressure on the spinal cord, increased extradural space, and reestablished CSF flow. ${ }^{51}$ The 3-level duraplasty treatment compression group showed significantly improved BBB scores when compared with injured controls, indicating significant improvement in locomotion. There is some evidence that early surgical decompression treatment via duraplasty with dural allograft can significantly affect motor function outcomes but further work on animal models is recommended.

\section{Study Limitations}

The contusion animal model of SCI used in the present study required performing a decompressive laminectomy to induce the injury at T-10, thus creating an immediate decompression effect. Therefore, this model does not exactly replicate the human SCI experience because the area of injury was not compressed once the impactor was removed. During preliminary studies, placement of a spacer on the dorsal spinal cord following the induced injury was attempted in order to ensure constant compression, but outcomes were inconsistent, and precise measurement of the force of injury induced was not possible, so a spacer was not included in the present study. 
Differences in surgical technique and tissue type may explain the discordant neurological outcomes for decompression following TBI versus SCI. ${ }^{22}$ In the supine position, pressure is essentially the same in the entire CSF compartment, but gravity gives rise to hydrostatic pressure gradients in the upright positon..$^{43}$ Additionally, it was not possible to predict which rats in the duraplasty treatment group would develop spinal cord compression caused by the hydrogel sealant, since all rats in these treatment groups underwent identical procedures and only a thin film of DuraSeal was used. DuraSeal is inappropriate for animal models of SCI due to mass effect of the sealant on the spinal cord. Additional studies should take into consideration the properties of the graft and sealant material used for dural repair in duraplasty.

\section{Conclusions}

Early surgical decompression did not significantly improve neurological function after severe thoracic SCI in rats and there is no evidence that increasing the number of decompression levels can improve outcomes. Decompressive laminectomy and durotomy without subsequent dural closure led to poor functional and histological outcomes following SCI. Fewer negative outcomes were associated with early decompressive duraplasty with graft but substantial functional improvements were not observed, so this technique warrants further investigation. When performing duraplasty treatments, precautions must be taken to minimize the risk of surgical complications as a result of dural repair techniques. Due to potential adverse effects, hydrogel dural sealants are not recommended for the repair of dural defects in a rodent model of spinal cord injury.

\section{References}

1. Aarabi B, Hesdorffer DC, Ahn ES, Aresco C, Scalea TM, Eisenberg HM: Outcome following decompressive craniectomy for malignant swelling due to severe head injury. J Neurosurg 104:469-479, 2006

2. Abla AA, Link T, Fusco D, Wilson DA, Sonntag VK: Comparison of dural grafts in Chiari decompression surgery: review of the literature. J Craniovertebr Junction Spine 1:29-37, 2010

3. Basso DM, Beattie MS, Bresnahan JC: A sensitive and reliable locomotor rating scale for open field testing in rats. J Neurotrauma 12:1-21, 1995

4. Blackburn SL, Smyth MD: Hydrogel-induced cervicomedullary compression after posterior fossa decompression for Chiari malformation. Case report. J Neurosurg 106 (4 Suppl):302-304, 2007

5. Boogaarts JD, Grotenhuis JA, Bartels RHMA, Beems T: Use of a novel absorbable hydrogel for augmentation of dural repair: results of a preliminary clinical study. Neurosurgery 57 (1 Suppl):146-151, 2005

6. Bourassa-Moreau É, Mac-Thiong JM, Li A, Ehrmann Feldman D, Gagnon DH, Thompson C, et al: Do patients with complete spinal cord injury benefit from early surgical decompression? Analysis of neurological improvement in a prospective cohort study. J Neurotrauma 33:301-306, 2016

7. Santana-Cabrera L, Pérez-Acosta G, Rodríguez-Escot C, Lorenzo-Torrent R, Sánchez-Palacios M: Complications of post-injury decompressive craniectomy. Int J Crit Illn Inj Sci 2:186-188, 2012

8. Cadotte DW, Singh A, Fehlings MG: The timing of surgical decompression for spinal cord injury. F1000 Med Rep 2:67, 2010

9. Conour LA, Murray KA, Brown MJ: Preparation of animals for research-issues to consider for rodents and rabbits. ILAR J 47:283-293, 2006

10. Cooper DJ, Rosenfeld JV, Murray L, Arabi YM, Davies AR, D'Urso P, et al: Decompressive craniectomy in diffuse traumatic brain injury. N Engl J Med 364:1493-1502, 2011

11. Cosgrove GR, Delashaw JB, Grotenhuis JA, Tew JM, Van Loveren H, Spetzler RF, et al: Safety and efficacy of a novel polyethylene glycol hydrogel sealant for watertight dural repair. J Neurosurg 106:52-58, 2007

12. Delamarter RB, Sherman J, Carr JB: Pathophysiology of spinal cord injury. Recovery after immediate and delayed decompression. J Bone Joint Surg Am 77:1042-1049, 1995

13. Detloff MR, Wade RE Jr, Houlé JD: Chronic at- and belowlevel pain after moderate unilateral cervical spinal cord contusion in rats. J Neurotrauma 30:884-890, 2013

14. Diatchenko L, Slade GD, Nackley AG, Bhalang K, Sigurdsson A, Belfer I, et al: Genetic basis for individual variations in pain perception and the development of a chronic pain condition. Hum Mol Genet 14:135-143, 2005

15. Dvorak MF, Noonan VK, Fallah N, Fisher CG, Finkelstein J, Kwon BK, et al: The influence of time from injury to surgery on motor recovery and length of hospital stay in acute traumatic spinal cord injury: an observational Canadian cohort study. J Neurotrauma 32:645-654, 2015

16. Fehlings MG, Vaccaro A, Wilson JR, Singh A, W Cadotte D, Harrop JS, et al: Early versus delayed decompression for traumatic cervical spinal cord injury: results of the Surgical Timing in Acute Spinal Cord Injury Study (STASCIS). PLoS One 7:e32037, 2012

17. Fouad K, Pearse DD, Tetzlaff W, Vavrek R: Transplantation and repair: combined cell implantation and chondroitinase delivery prevents deterioration of bladder function in rats with complete spinal cord injury. Spinal Cord 47:727-732, 2009

18. Fowler CJ: Investigation of the neurogenic bladder. J Neurol Neurosurg Psychiatry 60:6-13, 1996

19. Furlan JC, Noonan V, Cadotte DW, Fehlings MG: Timing of decompressive surgery of spinal cord after traumatic spinal cord injury: an evidence-based examination of pre-clinical and clinical studies. J Neurotrauma 28:1371-1399, 2011

20. Hofmeijer J, Kappelle LJ, Algra A, Amelink GJ, van Gijn J, van der Worp HB: Surgical decompression for space-occupying cerebral infarction (the Hemicraniectomy After Middle Cerebral Artery infarction with Life-threatening Edema Trial [HAMLET]): a multicentre, open, randomised trial. Lancet Neurol 8:326-333, 2009

21. Houle JD, Tessler A: Repair of chronic spinal cord injury. Exp Neurol 182:247-260, 2003

22. Huang X, Wen L: Technical considerations in decompressive craniectomy in the treatment of traumatic brain injury. Int $\mathbf{J}$ Med Sci 7:385-390, 2010

23. Hulsebosch CE, Hains BC, Crown ED, Carlton SM: Mechanisms of chronic central neuropathic pain after spinal cord injury. Brain Res Brain Res Rev 60:202-213, 2009

24. Hutchinson P, Timofeev I, Grainger S, Corteen E: The RESCUEicp decompressive craniectomy trial. Crit Care 13 (Suppl 1):P85, 2009

25. Iannotti C, Zhang YP, Shields LB, Han Y, Burke DA, Xu $\mathrm{XM}$, et al: Dural repair reduces connective tissue scar invasion and cystic cavity formation after acute spinal cord laceration injury in adult rats. J Neurotrauma 23:853-865, 2006

26. Jakeman LB (ed): Assessment of lesion and tissue sparing volumes following spinal cord injury, in Chen J, Xu XM, Xu ZC, et al (eds): Animal Models of Acute Neurological Injuries II. Injury and Mechanistic Assessments. New York: Humana Press, 2012, Vol 2, pp 417-442 
27. Kim KD, Wright NM: Polyethylene glycol hydrogel spinal sealant (DuraSeal Spinal Sealant) as an adjunct to sutured dural repair in the spine: results of a prospective, multicenter, randomized controlled study. Spine (Phila Pa 1976) 36:1906-1912, 2011

28. Koopmans GC, Deumens R, Honig WM, Hamers FP, Steinbusch HW, Joosten EA: The assessment of locomotor function in spinal cord injured rats: the importance of objective analysis of coordination. J Neurotrauma 22:214-225, 2005

29. Lee G, Lee CK, Bynevelt M: DuraSeal-hematoma: concealed hematoma causing spinal cord compression. Spine (Phila Pa 1976) 35:E1522-E1524, 2010

30. Lee SH, Park CW, Lee SG, Kim WK: Postoperative cervical cord compression induced by hydrogel dural sealant (DuraSeal). Korean J Spine 10:44-46, 2013

31. Li Y, Walker CL, Zhang YP, Shields CB, Xu XM: Surgical decompression in acute spinal cord injury: A review of clinical evidence, animal model studies, and potential future directions of investigation. Front Biol (Beijing) 9:127-136, 2014

32. Maikos JT, Elias RA, Shreiber DI: Mechanical properties of dura mater from the rat brain and spinal cord. J Neurotrauma 25:38-51, 2008

33. Mills CD, Hains BC, Johnson KM, Hulsebosch CE: Strain and model differences in behavioral outcomes after spinal cord injury in rat. J Neurotrauma 18:743-756, 2001

34. Mulder M, Crosier J, Dunn R: Cauda equina compression by hydrogel dural sealant after a laminotomy and discectomy: case report. Spine (Phila Pa 1976) 34:E144-E148, 2009

35. Mure PY, Galdo M, Compagnone N: Bladder function after incomplete spinal cord injury in mice: quantifiable outcomes associated with bladder function and efficiency of dehydroepiandrosterone as a therapeutic adjunct. J Neurosurg 100 (1 Suppl Spine):56-61, 2004

36. Nakae A, Nakai K, Yano K, Hosokawa K, Shibata M, Mashimo T: The animal model of spinal cord injury as an experimental pain model. J Biomed Biotechnol 2011:939023, 2011

37. National Spinal Cord Injury Statistical Center: Spinal Cord Injury (SCI) Facts and Figures at a Glance. Birmingham, AL: University of Alabama at Birmingham, 2016 (https:// www.nscisc.uab.edu/PublicDocuments/fact_figures_docs/ Facts\%202014.pdf) [Accessed July 13, 2016]

38. Nesic O, Lee J, Johnson KM, Ye Z, Xu GY, Unabia GC, et al: Transcriptional profiling of spinal cord injury-induced central neuropathic pain. J Neurochem 95:998-1014, 2005

39. Neuman BJ, Radcliff K, Rihn J: Cauda equina syndrome after a TLIF resulting from postoperative expansion of a hydrogel dural sealant. Clin Orthop Relat Res 470:1640-1645, 2012

40. Neumann M, Wang Y, Kim S, Hong SM, Jeng L, Bilgen M, et al: Assessing gait impairment following experimental traumatic brain injury in mice. J Neurosci Methods 176:34-44, 2009

41. Osbun JW, Ellenbogen RG, Chesnut RM, Chin LS, Connolly PJ, Cosgrove GR, et al: A multicenter, single-blind, prospective randomized trial to evaluate the safety of a polyethylene glycol hydrogel (Duraseal Dural Sealant System) as a dural sealant in cranial surgery. World Neurosurg 78:498-504, 2012

42. Piek J: Decompressive surgery in the treatment of traumatic brain injury. Curr Opin Crit Care 8:134-138, 2002

43. Qvarlander S, Sundstrom N, Malm J, Eklund A: Postural effects on intracranial pressure: modeling and clinical evaluation. J Appl Physiol (1985) 115:1474-1480, 2013

44. Rahimi-Movaghar V: Efficacy of surgical decompression in the setting of complete thoracic spinal cord injury. J Spinal Cord Med 28:415-420, 2005

45. Reddy S, Khalifian S, Flores JM, Bellamy J, Manson PN, Rodriguez ED, et al: Clinical outcomes in cranioplasty: risk factors and choice of reconstructive material. Plast Reconstr Surg 133:864-873, 2014

46. Romner B, Grände PO: Traumatic brain injury: Intracranial pressure monitoring in traumatic brain injury. Nat Rev Neurol 9:185-186, 2013

47. Sahuquillo J, Arikan F: Decompressive craniectomy for the treatment of refractory high intracranial pressure in traumatic brain injury. Cochrane Database Syst Rev (1):CD003983, 2006

48. Scheff SW, Rabchevsky AG, Fugaccia I, Main JA, Lumpp JE Jr: Experimental modeling of spinal cord injury: characterization of a force-defined injury device. J Neurotrauma 20:179-193, 2003

49. Schiariti M, Acerbi F, Broggi M, Tringali G, Raggi A, Broggi $\mathrm{G}$, et al: Two alternative dural sealing techniques in posterior fossa surgery: (polylactide-co-glycolide) self-adhesive resorbable membrane versus polyethylene glycol hydrogel. Surg Neurol Int 5:171, 2014

50. Siddiqui AM, Khazaei M, Fehlings MG: Translating mechanisms of neuroprotection, regeneration, and repair to treatment of spinal cord injury. Prog Brain Res 218:15-54, 2015

51. Smith JS, Anderson R, Pham T, Bhatia N, Steward O, Gupta $\mathrm{R}$ : Role of early surgical decompression of the intradural space after cervical spinal cord injury in an animal model. J Bone Joint Surg Am 92:1206-1214, 2010

52. Staykov D, Gupta R: Hemicraniectomy in malignant middle cerebral artery infarction. Stroke 42:513-516, 2011

53. Stiver SI: Complications of decompressive craniectomy for traumatic brain injury. Neurosurg Focus 26(6):E7, 2009

54. Strömqvist F, Jönsson B, Strömqvist B: Dural lesions in decompression for lumbar spinal stenosis: incidence, risk factors and effect on outcome. Eur Spine J 21:825-828, 2012

55. Tasiou A, Vagkopoulos K, Georgiadis I, Brotis AG, Gatos H, Fountas KN: Cranioplasty optimal timing in cases of decompressive craniectomy after severe head injury: a systematic literature review. Interdiscip Neurosurg 1:107-111, 2014

56. Than KD, Baird CJ, Olivi A: Polyethylene glycol hydrogel dural sealant may reduce incisional cerebrospinal fluid leak after posterior fossa surgery. Neurosurgery 63 (1 Suppl 1):ONS182-ONS187, 2008

57. Thavarajah D, De Lacy P, Hussain R, Redfern RM: Postoperative cervical cord compression induced by hydrogel (DuraSeal): a possible complication. Spine (Phila Pa 1976) 35:E25-E26, 2010

58. Timofeev I, Hutchinson PJ: Outcome after surgical decompression of severe traumatic brain injury. Injury 37:11251132,2006

59. Vahedi K, Vicaut E, Mateo J, Kurtz A, Orabi M, Guichard JP, et al: Sequential-design, multicenter, randomized, controlled trial of early decompressive craniectomy in malignant middle cerebral artery infarction (DECIMAL Trial). Stroke 38:2506-2517, 2007

60. Watson C, Paxinos G, Kayalioglu G (eds): The Spinal Cord, ed 1. London: Elsevier, 2008

61. Weiner GM, Lacey MR, Mackenzie L, Shah DP, Frangos SG, Grady MS, et al: Decompressive craniectomy for elevated intracranial pressure and its effect on the cumulative ischemic burden and therapeutic intensity levels after severe traumatic brain injury. Neurosurgery 66:1111-1119, 2010

62. Wing PC: Early acute management in adults with spinal cord injury: a clinical practice guideline for health-care providers. Who should read it? J Spinal Cord Med 31:360-360, 2008

63. Woods BI, Hohl J, Lee J, Donaldson W III, Kang J: Laminoplasty versus laminectomy and fusion for multilevel cervical spondylotic myelopathy. Clin Orthop Relat Res 469:688695, 2011

64. Wright NM, Park J, Tew JM, Kim KD, Shaffrey ME, Cheng J, et al: Spinal sealant system provides better intraoperative watertight closure than standard of care during spinal 
surgery: a prospective, multicenter, randomized controlled study. Spine (Phila Pa 1976) 40:505-513, 2015

65. Wu J, Raver C, Piao C, Keller A, Faden AI: Cell cycle activation contributes to increased neuronal activity in the posterior thalamic nucleus and associated chronic hyperesthesia after rat spinal cord contusion. Neurotherapeutics 10:520-538, 2013

66. Zweckberger K, Stoffel M, Baethmann A, Plesnila N: Effect of decompression craniotomy on increase of contusion volume and functional outcome after controlled cortical impact in mice. J Neurotrauma 20:1307-1314, 2003

\section{Disclosures}

This study was financed by the Reynolds Family Spine Laboratory. DuraSeal is a registered trademark and DuraSeal Exact spine sealant was donated by Integra LifeSciences Corp. to the laboratory for use in this study. Dr. Heary reports receipt of royalties from DePuy Spine, Zimmer Inc., and Thieme Medical Publishers.

\section{Supplemental Information}

Previous Presentations

Portions of this work were presented in electronic poster format at the 84th AANS Annual Scientific Meeting in Chicago, Illinois, April 30-May 4, 2016.

\section{Author Contributions}

Conception and design: Heary, Jalan, Saini. Acquisition of data: Jalan, Saini. Analysis and interpretation of data: Heary, Jalan, Saini, Zaidi, Elkabes. Drafting the article: Jalan, Saini, Zaidi. Critically revising the article: all authors. Reviewed submitted version of manuscript: all authors. Approved the final version of the manuscript on behalf of all authors: Heary. Statistical analysis: Jalan, Saini, Zaidi, Pallottie. Administrative/technical/material support: all authors. Study supervision: Heary, Jalan, Saini, Elkabes.

\section{Correspondence}

Robert F. Heary, Department of Neurological Surgery, Rutgers, The State University of New Jersey-New Jersey Medical School, 90 Bergen St., Ste.8100, Newark, NJ 07103. email: heary@njms. rutgers.edu. 